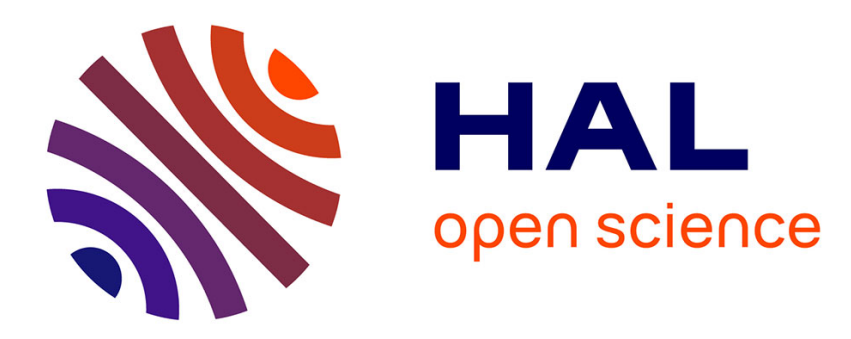

\title{
Coupling, Reinforcement, and Speciation
}

Roger Butlin, Carole Smadja

\section{To cite this version:}

Roger Butlin, Carole Smadja. Coupling, Reinforcement, and Speciation. American Naturalist, 2018, 191 (2), pp.155-172. 10.1086/695136 . hal-01945350

\section{HAL Id: hal-01945350 \\ https://hal.science/hal-01945350}

Submitted on 5 Dec 2018

HAL is a multi-disciplinary open access archive for the deposit and dissemination of scientific research documents, whether they are published or not. The documents may come from teaching and research institutions in France or abroad, or from public or private research centers
L'archive ouverte pluridisciplinaire HAL, est destinée au dépôt et à la diffusion de documents scientifiques de niveau recherche, publiés ou non, émanant des établissements d'enseignement et de recherche français ou étrangers, des laboratoires publics ou privés.

\section{(c)(1)}

Distributed under a Creative Commons Attribution| 4.0 International License 
SYNTHESIS

\title{
Coupling, Reinforcement, and Speciation
}

\author{
Roger K. Butlin ${ }^{1,2, *}$ and Carole M. Smadja ${ }^{1,3}$
}

1. Stellenbosch Institute for Advanced Study, Wallenberg Research Centre at Stellenbosch University, Stellenbosch 7600, South Africa; 2. Department of Animal and Plant Sciences, The University of Sheffield, Sheffield S10 2TN, United Kingdom; and Department of Marine Sciences, University of Gothenburg, Tjärnö SE-45296 Strömstad, Sweden; 3. Institut des Sciences de l'Evolution, Unité Mixte de Recherche 5554 (Centre National de la Recherche Scientifique-Institut de Recherche pour le Développement-École pratique des hautes études), Université de Montpellier, 34095 Montpellier, France

Submitted March 15, 2017; Accepted August 28, 2017; Electronically published December 15, 2017

AвSTRACT: During the process of speciation, populations may diverge for traits and at their underlying loci that contribute barriers to gene flow. These barrier traits and barrier loci underlie individual barrier effects, by which we mean the contribution that a barrier locus or trait- or some combination of barrier loci or traits - makes to overall isolation. The evolution of strong reproductive isolation typically requires the origin of multiple barrier effects. Critically, it also requires the coincidence of barrier effects; for example, two barrier effects, one due to assortative mating and the other due to hybrid inviability, create a stronger overall barrier to gene flow if they coincide than if they distinguish independent pairs of populations. Here, we define "coupling" as any process that generates coincidence of barrier effects, resulting in a stronger overall barrier to gene flow. We argue that speciation research, both empirical and theoretical, needs to consider both the origin of barrier effects and the ways in which they are coupled. Coincidence of barrier effects can occur either as a by-product of selection on individual barrier effects or of population processes, or as an adaptive response to indirect selection. Adaptive coupling may be accompanied by further evolution that enhances individual barrier effects. Reinforcement, classically viewed as the evolution of prezygotic barriers to gene flow in response to costs of hybridization, is an example of this type of process. However we argue for an extended view of reinforcement that includes coupling processes involving enhancement of any type of additional barrier effect as a result of an existing barrier. This view of coupling and reinforcement may help to guide development of both theoretical and empirical research on the process of speciation.

Keywords: species, reproductive isolation, gene flow, adaptation, linkage disequilibrium.

\footnotetext{
* Corresponding author; e-mail: r.k.butlin@sheffield.ac.uk. ORCIDs: Butlin, http://orcid.org/0000-0003-4736-0954; Smadja, http://orcid .org/0000-0002-7285-1408.
}

Am. Nat. 2018. Vol. 191, pp. 155-172. (c) 2017 by The University of Chicago. 0003-0147/2018/19102-57614\$15.00. All rights reserved. This work is licensed under a Creative Commons Attribution 4.0 International License (CC BY 4.0), which permits reuse of the work with attribution.

DOI: $10.1086 / 695136$

\section{Introduction}

Understanding how reproductive isolation evolves is key to our understanding of speciation (Mayr 1963; Coyne and Orr 2004; our use of terms is defined in table A1). Empirical and theoretical studies have significantly advanced our knowledge on how individual traits and loci diverge and contribute to an overall barrier to gene flow and have shown that individual contributions may be established without great difficulty (Barton 2013). These barrier traits and barrier loci underlie individual barrier effects, by which we mean the contribution that a barrier locus or trait—or some combination of barrier loci or traits - makes to overall isolation. In some cases, a single locus or trait may contribute to the barrier independently (e.g., a locus or trait contributing to local adaptation or to the timing of reproduction and, consequently, to assortative mating). In other cases, loci or traits may only have barrier effects due to their interactions with other loci or traits (e.g., two loci involved in a Dobzhansky-Muller incompatibility only have a barrier effect together; divergence between populations in a male signal trait only results in assortative mating and so has a barrier effect, once a female preference trait diverges between the same populations). Individual barrier effects typically restrict gene flow only at and near the loci responsible for them because recombination can separate alleles at other loci from the barrier loci.

Barrier effects can evolve through the spread of incompatible alleles via drift or positive selection in one population (mutation order; Schluter 2009) or by divergent natural or sexual selection between populations (e.g., Rundle and Nosil 2005; Sobel et al. 2009; Nosil 2012), in spatial contexts ranging from zero gene flow (allopatry) to high and continuous gene flow (sympatry; Coyne and Orr 2004; Bolnick and Fitzpatrick 2007). Both pre- and postzygotic barrier effects can be generated in these ways, but because the barrier effects require divergence in allele frequency or trait mean between populations, they correspond to two-allele barrier effects. Alternatively, a new allele might contribute to a barrier effect when it spreads throughout the species, 
and this will form a one-allele barrier effect (Felsenstein 1981). Since Felsenstein's (1981) landmark article, this distinction has been central to the genetics of speciation because there are fewer obstacles to the evolution of one-allele effects, and therefore, they make speciation more likely (e.g., Kirkpatrick and Servedio 2002; Coyne and Orr 2004). It is also critical for our discussion here, and so we expand on it below.

A two-allele effect requires divergence in allele frequency between populations at one or more loci or divergence in a trait (Servedio 2000). Traits contributing to local adaptation, loci contributing to Dobzhansky-Muller incompatibilities, and sexual signal traits involved in assortative mating are typical contributors to barriers of this type. The evolution of a two-allele effect can be opposed by gene flow, and for loci or traits under indirect selection, it may require the maintenance of linkage disequilibrium despite recombination (Smadja and Butlin 2011). A one-allele barrier effect does not require divergence between populations and so is not opposed by gene flow or recombination, key obstacles to speciation involving two-allele effects. Felsenstein (1981) gave the examples of an allele that reduces migration and an allele that enhances mating between similar individuals with respect to a trait under divergent selection. In each case, reproductive isolation is enhanced by the spread of the trait or allele through both populations. Although the one-allele model is most often considered for prezygotic barriers, both types of barrier effect can, in principle, underlie either preor postzygotic isolation. One-allele barrier effects are generally considered to arise in response to existing barriers (i.e., as a form of reinforcement [Felsenstein 1981] and usually functioning only to enhance the effects of other barrier loci, i.e., acting as modifiers [e.g., Barton and de Cara 2009]). But this need not be the case: they can create barrier effects de novo (cf. Servedio 2000; Bank et al. 2012). For example, an allele that causes a plastic response in flowering time to varying soil conditions might be advantageous everywhere but generate a barrier effect at an environmental boundary (as has been suggested for Howea palms; Savolainen et al. 2006). Finally, a one-allele barrier effect will usually have a genome-wide impact on gene flow: it influences all loci equally because no locus can recombine away from its effect once fixed, unless it acts as a modifier, in which case the barrier effect may be limited to the region around the barrier locus whose effect is being modified.

It is possible for a single barrier effect (either one- or twoallele) to be strong, in principle even causing complete reproductive isolation. Possible examples are the effects of changes in ploidy in plants (Soltis et al. 2010) or coil direction in snails (Gittenberger et al. 2012). However, most sister-species pairs, even when recently evolved, differ in multiple traits, and multiple barrier effects contribute to the overall barrier between them (Coyne and Orr 2004). This is consistent with theory. Even though the barrier effect at a single barrier locus may be strong - that is, mating is far from random or hybrid fitness is low-its effect on gene exchange for the majority of the genome is expected to be weak because of recombination (except for some one-allele effects). Typically, it is only when multiple barrier effects are combined - such that neutral loci throughout the genome are influenced by barrier loci- that the overall barrier becomes strong (Barton 1983, 2013; Barton and Bengtsson 1986; Barton and de Cara 2009; Feder et al. 2012a; Flaxman et al. 2014). Thus, speciation, which relies on the evolution of a strong overall barrier to gene exchange, depends not only on the evolution of individual barrier effects but also, critically, on processes that couple these barrier effects together.

In the recent literature, coupling of barrier effects has been discussed as a part of the speciation process (e.g., Abbott et al. 2013; Barton 2013; Seehausen et al. 2014), but "coupling" has not been clearly defined and there is no common framework relating it to other elements of speciation. If coupling of different barrier effects is needed to generate a strong and stable overall barrier to gene exchange, then it is critical that speciation research embraces this process, in order to gain insight into the conditions under which it occurs. Here, we consider the existing literature on coupling, propose a general definition of this process that includes one-allele mechanisms, and then classify different possible scenarios for coupling. By doing so, we also clarify its relationship with other concepts, particularly reinforcement (Dobzhansky 1937; Butlin 1987; Servedio and Noor 2003), and identify possible future research directions. Our aim is to set out a coherent view of the roles that coupling can play in the speciation process. We hope that this will aid effective communication in the field and encourage the further exploration of the roles and conditions of coupling at both the theoretical and empirical levels.

\section{Coupling and Speciation \\ Historical Views of Coupling}

The idea that association among different barriers to gene flow is key to the speciation process is an old one: it underlies the notion of coadapted gene complexes evolving during allopatric speciation (Mayr 1963), and in the context of divergence with gene flow, early theory emphasized the importance of the evolution of linkage disequilibrium (LD) among barrier loci (e.g., Maynard Smith 1966; Felsenstein 1981). In 1983, Barton introduced the term "coupling" in the context of hybrid zones, defining a "coupling coefficient" (the ratio of total selection to total recombination) that governs the extent to which loci behave independently in multilocus clines. The strength of the overall barrier is much greater when coupling of clines occurs. The central idea was that a buildup of LD among selected loci increases the efficacy of selection be- 
cause each locus is indirectly influenced by the selection on other loci in addition to its own fitness effects (Barton 1983); as a result, the barrier to gene flow generated by each selected locus is stronger and it is more difficult for neutral alleles to flow past the cline than it would be without strong LD (Barton and Bengtsson 1986).

Not until two decades later did a series of review articles and theoretical studies popularize this idea and extend it to other speciation contexts. Considering coupling outside the context of hybrid zones, Barton and de Cara (2009) analyzed the conditions under which coupling can occur and emphasized the generality of coupling among different types of barrier effects, whether pre- or postzygotic. Servedio (2009) and Smadja and Butlin (2011) highlighted the role of linkage disequilibrium and trait associations more generally, in the evolution of strong reproductive isolation. Bierne et al. (2011) drew attention to coupling between existing intrinsic and extrinsic barrier effects, and although they considered primarily spatial interactions, they also argued that coupling is important in nonspatial dimensions. Recently, the term "coupling" has been used more widely in discussions of speciation processes (e.g., Abbott et al. 2013; Seehausen et al. 2014) and empirical studies (e.g., Gagnaire et al. 2013; Seehausen 2013; Seehausen and Wagner 2014; Vines et al. 2016), reflecting an increasing recognition of its importance in the evolution of strong reproductive isolation and, thus, in the likelihood of speciation. However, because the term "coupling" has not been given a technical definition and clear delimitations, we are concerned that its actual meaning varies among authors and does not always encompass the diversity of mechanisms that could usefully be included. Although most people would agree with the idea that coupling refers to "the build-up of associations between several traits or loci that are involved in reproductive isolation [that] strengthens the total barrier to gene flow between diverging populations" (Seehausen et al. 2014, p. 184), this description lacks precision and does not set clear boundaries to the concept. Some authors explicitly restrict coupling to a genomic context (genomic coupling; Seehausen et al. 2014), consider it equivalent to "the evolution of linkage disequilibrium” (e.g., Gagnaire et al. 2013; Seehausen et al. 2014), or restrict it to two-allele barrier effects (e.g., Barton and de Cara 2009). Moreover, because conditions for coupling have mostly been explored theoretically in contexts where coupling is adaptive - that is, where it evolves as a response to selection in the presence of gene flow (e.g., Barton and de Cara 2009; Bierne et al. 2011) —other possible modalities of coupling have largely been ignored.

\section{Toward a General Definition of Coupling}

In order to provide a definition of coupling that is applicable across all speciation processes, we first introduce some additional properties of barrier effects, contrast one- and two- allele barrier effects, and then consider the role of linkage disequilibrium.

Coincidence of Barrier Effects. Individual loci or traits can contribute to the overall barrier to gene exchange through their barrier effects. Each individual barrier effect will define a pair of populations, because it reduces gene flow between subsets of individuals, but the populations defined by different barrier effects need not have coincident boundaries. Incompatibilities generated under the mutation order mechanism will initially form barriers wherever the two spreading alleles happen to meet. This depends only on where the mutations occurred and on their rates of spread. Each locus responding to divergent selection will contribute to a barrier effect at a discontinuity in the relevant environmental axis. This need not separate populations spatially; populations could be partitioned on a seed-size axis for a locus affecting beak form, for example. If different features of the environment vary more or less independently, then the barriers due to divergent selection will form in different places and between different populations as defined by nonspatial variables. Similarly, one-allele processes will generate barriers related to relevant environmental features that need not covary. The initial, homogeneous population will become genetically and phenotypically subdivided, potentially into many units defined by different combinations of barrier effects: for example, an incompatibility generated by genomic conflict might define two spatial subpopulations independently from subpopulations defined by divergent selection across an environmental discontinuity and a one-allele barrier effect separating subpopulations according to reproductive season, resulting in eight recognizable units in total. With many barrier effects but no coincidence of barrier effects, the overall result will be a simple accumulation of reproductive isolation with geographic or ecological distance (Barton and de Cara 2009; Barton 2013). The European corn borer, Ostrinia nubilalis, provides a concrete example: voltinism, pheromone signaling, and host-plant association all provide barrier effects that define populations (uni- vs. bivoltine, $\mathrm{E}$ vs. $\mathrm{Z}$ pheromone races, mugwort vs. maize), but these populations do not coincide and thus no strong barrier to gene flow exists between any of them (Dopman et al. 2010; Orsucci et al. 2016). Strong barriers to gene flow will evolve only if multiple barrier effects become coincident.

Coupling, Two-Allele Models, and One-Allele Models. In the existing literature, coupling is mostly discussed for two-allele barrier effects where the buildup of LD between barrier loci indicates the coincidence of the associated barrier effects (e.g., Barton and de Cara 2009; Bierne et al. 2011). We argue that it is important to generalize the concept of coupling further: coupling should be extended to any type of barrier effect that contributes to speciation. From our per- 
spective, it is coincidence of the barrier effects that is crucial for reproductive isolation, rather than coincidence of the traits or allele frequencies. Thus, a one-allele barrier effect may be coupled to a two-allele barrier effect: for example, imprinting on the natal habitat (a one-allele form of habitat preference) may lead to a prezygotic barrier effect that may evolve to be coincident with a barrier effect due to local adaptation (a two-allele, postzygotic barrier effect), and this may relate to a nonspatial habitat axis, such as different host plants used by an insect herbivore.

Coupling and Linkage Disequilibrium. LD between barrier loci is necessarily increased when two-allele barrier effects become coincident, whatever the process generating coincidence. However, coincidence of barrier effects and increased LD among barrier loci should not be considered as equivalent for two reasons. Suppose an allele for natal habitat imprinting spreads to fixation in two populations occupying different niches, creating a one-allele barrier effect. The presence of this barrier may facilitate local adaptation, generating coincident two-allele barrier effects. But since there is no genetic variation at the imprinting locus, there can be no LD. So, although LD may sometimes be required for the spread of a one-allele effect (e.g., Servedio 2000), coupling can involve one-allele barriers that are not in $\mathrm{LD}$ with other barriers, especially where the one-allele effect is fixed before a subsequent barrier evolves. Also, it is important to distinguish the processes that bring barrier effects together and the various ways in which LD might build up: for example, LD across populations is an inevitable result of allopatry, within-population LD might occur due to admixture, or selection might favor $\mathrm{LD}$ where there is gene flow and selection against hybrids (e.g., Felsenstein 1981; Barton and de Cara 2009). Simply equating buildup of LD with coupling is not sufficient. Barton (2013) has also suggested that coupling is more general than just the buildup of LD in admixed populations. Understanding how LD builds up remains an important part of research on coupling, especially since many scenarios of speciation will include two-allele mechanisms and at least some episodes of gene flow (Smadja and Butlin 2011), but this should be included in a larger set of coupling processes that build strong overall barriers to gene exchange by making multiple barrier effects coincide.

These considerations lead us to propose a definition of "coupling" that is general while being compatible with the different uses of the term in the existing literature and with other terminology (see table A1): coupling is any process that generates coincidence of barrier effects, resulting in a stronger overall barrier to gene flow.

We intentionally focus on barrier effects in order to include one- as well as two-allele models, and focus on the outcome - that is, the coincidence of barrier effects (spatial or otherwise) - to allow the inclusion of all the possible mechanisms that can generate coupling (see "A Classification of Coupling Processes") and to foster inclusion of all the possible factors (genetic architecture, selection, etc.) favoring coupling (see "How Can the Role of Coupling in Speciation Be Tackled Empirically? Current Knowledge and Future Directions"). "Coincident," in this context, is not restricted to have a spatial meaning: it can be in any dimension, such as in time or in some niche dimension.

\section{A Classification of Coupling Processes}

Our perspective on coupling argues for inclusion of a range of processes in which selection for coincidence is not always required. Building on existing theoretical studies and ideas from the literature, we propose a classification of coupling processes that highlights scenarios where coupling is an adaptive process in which coincidence of barrier effects is favored by selection but also draws attention to scenarios where coincidence evolves as a by-product of other processes.

\section{Coincidence of Barrier Effects as a By-product}

The coincidence of barrier effects may be a by-product of the simultaneous evolution of barrier effects, of population processes, or of selection acting independently on the individual barrier loci or traits. Because none of these scenarios requires selection for coincidence per se, we will classify these processes as "by-product coupling." We see four broad categories of process that might cause by-product coupling and so contribute toward speciation (fig. 1A, I-IV). Barton (2013) has previously argued that coupling can be automatic in situations II and III of fig. $1 A$.

Coincidence as a By-product of the Simultaneous Evolution of Barrier Effects. In some cases, the spread of an allele may create more than one barrier effect simultaneously, necessarily resulting in coincidence (fig. $1 \mathrm{~A}$, I). This will occur in the case of multiple-effect traits that contribute to more than one barrier effect and where the allele has pleiotropic effects on more than one trait, each of which contributes to a barrier effect (Smadja and Butlin 2011). In addition, a second barrier effect may be introduced by a neutral allele hitchhiking to high frequency in one subpopulation with a strongly selected locus due to linkage disequilibrium generated by mutation. In other words, the selective sweep of a new, locally advantageous mutation may happen to take a nearby allele to high frequency, and this allele may contribute to a second barrier effect. Hitchhiking of an allele contributing to hybrid inviability with an allele for copper tolerance in Mimulus is a good example of this latter process (Wright et al. 2013; Baack et al. 2015). 


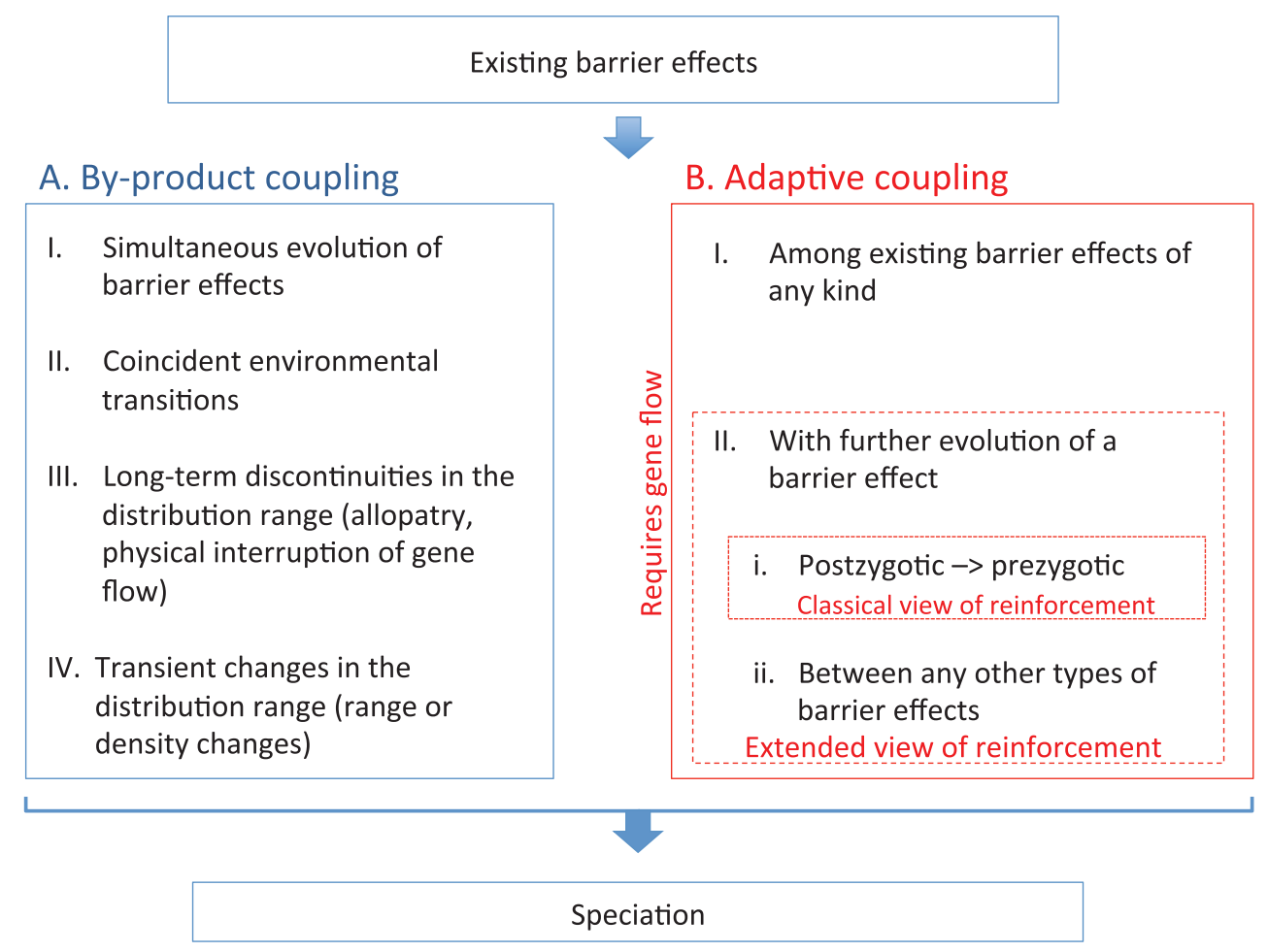

Figure 1: Classification of coupling processes that can contribute toward speciation. A, By-product coupling (blue box) includes four broad categories of process (I-IV). B, Adaptive coupling (red box) may occur with (I) or without (II) further evolution of barrier effects, the latter category including different delimitations of the reinforcement concept. Adaptive coupling requires gene flow. A typical speciation process may involve both by-product and adaptive coupling.

Coincidence as a By-product of Divergent Selection Acting Independently on Different Barrier Effects but at Coincident Environmental Boundaries. Where environmental discontinuities, in space, time, or some habitat dimension, influence divergent selection on multiple traits, coincident barrier effects may evolve (fig. $1 \mathrm{~A}, \mathrm{II}$ ). These may also be coincident with one-allele barrier effects at the same discontinuities. The barrier effects may influence any component of reproductive isolation, pre- or postzygotic. The coincidence of barrier effects requires no more than independent selection on the different loci or traits, but it results in a stronger overall barrier than would be caused by selection on any single trait. This is equivalent to the argument by Rice and Hostert (1993) and Nosil and colleagues (Nosil et al. 2009; Nosil 2012) that multifarious selection, resulting in divergence of multiple loci or traits across the same habitat boundary, is likely to generate greater progress toward speciation than strong selection on individual traits. Coincidence of different dimensions of selection across habitat boundaries may well be common: examples are provided by host races of the apple maggot fly, Rhagoletis pomonella (Michel et al. 2010), and lake-stream pairs of sticklebacks, Gasterosteus aculeatus (Marques et al. 2016).
Coincidence as a By-product of Long-Term Discontinuities in the Distribution Range. An alternative mechanism requires partial or complete subdivision of the range by areas in which the species is at low density or that it cannot occupy (i.e., partial extrinsic barriers or allopatry; fig. $1 A$, III). Wiens (2004) has argued that such disjunctions in the range are not really extrinsic because the failure of the organism to occupy them successfully is actually a result of its biology (a valley creates a disjunction for a montane species because of its adaptation to high altitude). He has also argued that since these disjunctions interrupt gene flow, they should be considered as the initial stage in speciation. We sympathize with these views, particularly because disjunctions can also occur in nonspatial dimensions, such as between odd- and even-year salmon cohorts (Limborg et al. 2014) or periodical cicada broods (Cooley et al. 2003) that are separated temporally. From the perspective of coupling, disjunctions are important because they delay the spread of new mutations and so are often the sites at which independently arisen mutations meet and contribute to barrier effects. They can also trap barrier effects formed elsewhere, if these effects are not constrained in location by divergent selection, because such barrier effects tend to move to areas of low population density 
(Barton and Hewitt 1985; Bierne et al. 2011). Coincidence of barrier effects, therefore, tends to occur at partial or complete population disjunctions for barrier effects originated by mutation-order processes, but in nature, these disjunctions may also correspond to environmental boundaries resulting in coupling also with one-allele barrier effects and effects due to divergent selection. Allopatric divergence is simply an extreme of this general form of by-product coupling.

Coincidence as a Result of Transient Changes in the Distribution Range. Hewitt (1989) suggested a further process than can enhance coincidence of barrier effects (fig. 1A, IV). A widely distributed population may be subdivided into multiple different units by the intersection of independently evolved barrier effects, as described above. Now consider what happens when the range of the population is reduced, by environmental change, to a small number of refugia: the refugial populations will, typically, differ from one another by multiple barrier effects. The barrier effects become coincident as a result of range contraction (cf. Barton 2013). When range expansion - in the next interglacial period, for example - causes descendants of the refugial populations to meet, they will experience a strong overall barrier as a result of these coupled effects. The strong barriers seen at some hybrid zones (e.g., Bombina toads; Szymura and Barton 1991) may be a result of repetition of this process across multiple glacial cycles (Hewitt 1996), although in most cases, other processes, falling into the category of adaptive coupling, are typically involved. Hybrid zones involving multiple chromosomal fusions but lacking observed ecological differentiation between races may be formed more exclusively in this way (e.g., in Sorex shrews; Searle 1993).

\section{Coincidence as an Adaptive Response to Selection}

Where selection favors coincidence between barrier effects, we propose the term "adaptive coupling." We find it helpful to distinguish two major forms of adaptive coupling, those processes in which two existing barrier effects become coincident and those processes where the existence of one barrier effect promotes the origin or enhancement of a second, coincident effect. Note that evolution of one barrier effect may sometimes reduce the chances of another barrier evolving (see below).

Adaptive Coupling of Existing Barrier Effects. It has been known for a long time that spatial clines for two barrier loci will attract one another (Slatkin 1975; Barton 1983). This process is illustrated for the simple case of two loci, each with selection against heterozygotes, in figure 2 . The attraction occurs because dispersal generates linkage disequilibrium wherever two loci both show gradients in allele frequency (i.e., where clines overlap). When there is $\mathrm{LD}$, direct selection on each locus is supplemented by indirect selection as a result of association with the other locus. This effect is asymmetrical and makes the clines move toward one another until their centers are coincident. Each cline is steepened by this process because each locus experiences stronger selection (direct + indirect). Thus, both the genomically local and overall barriers to gene flow are increased, potentially generating strongly stepped clines for loci throughout the genome (as in Bombina; Szymura and Barton 1991). Where this occurs, hybrid zones present a strong barrier to gene flow (Barton and Gale 1993), in marked contrast to hybrid zones where selection is weaker relative to recombination and coupling does not occur (e.g., Chorthippus parallelus; Shuker et al. 2005). The process of attraction between clines is an example of adaptive coupling of existing barrier effects (fig. $1 \mathrm{~B}, \mathrm{I}$ ). We distinguish it from by-product coupling processes because selection acts directly to cause coupling. In this case, coincidence of two clines is equivalent to an increase in LD between a pair of loci: it reduces the number of unfit heterozygous genotypes produced and so increases overall mean fitness. This component of selection is distinct from that operating to maintain clines at the individual loci. Because it increases mean fitness, coupling can be considered adaptive-hence the term "adaptive coupling."

Attraction of clines occurs whether they are maintained by selection against heterozygotes, selection against recombinants, or divergent selection across environmental boundaries (Bierne et al. 2011). An equivalent process also occurs across nonspatial boundaries because gene flow across such boundaries can also generate LD and, thus, asymmetric selection pressures. Felsenstein's (1981) highly influential model considers this form of adaptive coupling. Barrier effects result from selection on two loci $(\mathrm{B} / \mathrm{b}, \mathrm{C} / \mathrm{c})$ underlying adaptation to different components of the environment. Their effects are coincident because they respond to the same environmental discontinuity. A further barrier effect is due to a locus (A/a) that causes assortative mating but is not under direct selection. If all three loci have allele frequencies of 0.5 (in the case where the two environmental components make equal contributions to the total population), then selection favors $\mathrm{LD}$ between $\mathrm{A}$ and $\mathrm{BC}$, and the barrier effect of $\mathrm{A}$ evolves toward coincidence with the $\mathrm{BC}$ barrier (either the haplotype $\mathrm{ABC}$ dominates in one environment and $\mathrm{abc}$ in the other, or $\mathrm{aBC}$ and $\mathrm{Abc}$ dominate). This strengthens the overall barrier between the subpopulations occupying the two environments without the individual barrier effects changing. This is also a case of adaptive coupling of existing barrier effects (fig. $1 B, \mathrm{I}$ ) and shows that the process can apply to prezygotic components of reproductive isolation.

More recently, Barton and de Cara (2009) have shown that coupling of existing two-allele barrier effects is a very general process that can occur even in unstructured pop- 


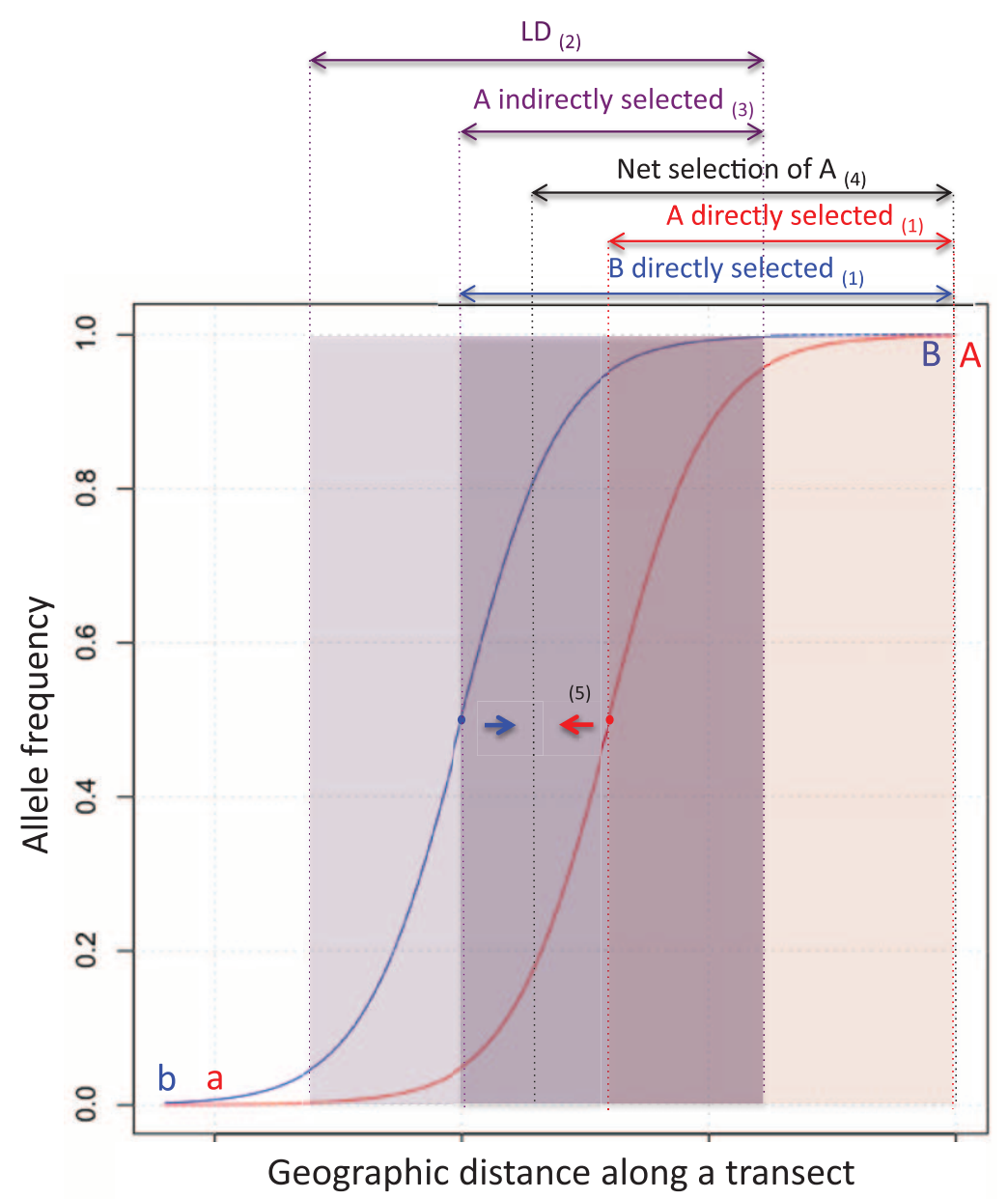

Figure 2: Coupling of existing barrier effects in a spatial context. The process is illustrated here for the simple case of two loci, each with selection against heterozygotes: (1) allele A is favored by direct selection in the right part of the red cline, and allele B is favored by direct selection in the right part of the blue cline; (2) linkage disequilibrium (LD) between loci A and B is created by dispersal where clines overlap; (3) LD generates indirect selection (here shown on allele A in the part of the cline where allele B is under direct selection); (4) net selection favors an increase in frequency of A in the area indicated; and (5) the cline for locus A moves to the left (red arrow). A mirror-image process will operate for the cline for locus B (blue arrow) until the clines coincide.

ulations and for any form of barrier effect, including both pre- and postzygotic components of reproductive isolation in any combination (fig. 3, case 1). For these barrier effects, selection favors LD between barrier loci either because increased variance in compatibility increases mean fitness or because LD reduces the opportunity for recombination to generate unfit allele combinations. Because it is driven by the production of unfit hybrid genotypes, adaptive coupling cannot occur in allopatry.

We extend this idea further to suggest that existing oneallele barrier effects can also be coupled with existing twoallele barrier effects (fig. 3, case 2). An example might be natal habitat imprinting coupling to local adaptation (e.g., Beltman and Metz 2005). Here the process appears to be different because it cannot be driven by LD (at least where the barrier al- lele is fixed everywhere at the locus underlying the one-allele barrier effect at the time of coupling). Instead, we expect a one-allele barrier effect to operate exactly like a population disjunction by creating a partial barrier to gene flow. A cline for a two-allele barrier locus that overlaps such a partial barrier will experience asymmetric gene flow and so will move to become coincident with the one-allele barrier effect. The coincidence will reduce the production of unfit hybrid genotypes at the two-allele barrier locus and so increase mean fitness. Thus, although this process appears to depend on the balance between selection and gene flow rather than on an additional component of selection, it is distinct from by-product coupling because the existence of the one-allele barrier effect creates the conditions for coupling with the two-allele effect, rather than both barrier effects responding simply to external 


\begin{tabular}{|c|c|c|}
\hline & Two-allele models & One-allele models \\
\hline $\begin{array}{l}\text { Adaptive coupling } \\
\text { of existing barrier } \\
\text { effects }\end{array}$ & $\begin{array}{c}1 . \\
\text { Post + pre } \\
\text { Post + post } \\
\text { Pre + pre }\end{array}$ & $\begin{array}{c}2 . \\
\text { Post + pre } \\
\text { Post + post } \\
\text { Pre + pre }\end{array}$ \\
\hline $\begin{array}{l}\text { Adaptive coupling } \\
\text { with further } \\
\text { evolution of one } \\
\text { barrier effect } \\
\text { (extended view of } \\
\text { reinforcement) }\end{array}$ & re & $\pi$ pre \\
\hline
\end{tabular}

Figure 3: Models of adaptive coupling. These models are classified according to whether coincidence occurs between already evolved barrier effects or with the further evolution of a barrier effect and according to the types of effects being modeled (two- or one-allele barrier effects). For each situation, different possible combinations of postzygotic and prezygotic barrier effects can become coupled. Some combinations have already been modeled (unshaded), but others still need to be explored theoretically (shaded). Although we distinguish pre- and postzygotic barrier effects in line with traditional usage, we note that the boundary at zygote formation may not be critical for coupling or for further evolution of barrier effects (see text). A plus sign indicates coupling without enhancement, an arrow indicates indirect selection

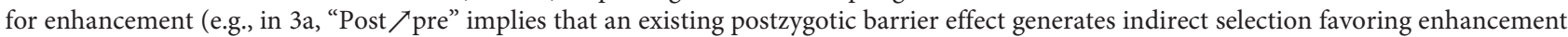
of a prezygotic barrier effect). 1, Barton and de Cara (2009). 2, To be explored. 3a, For example, Barton and de Cara (2009); Servedio and Kirkpatrick (1997); Liou and Price (1994); Servedio (2000). 3b, Servedio (2001). 3c-3d, To be explored. 4a, For example, Kirkpatrick (2000); Cain et al. (1999); Kelly and Noor (1996); Sanderson (1989); Servedio (2000). 4b-4d, To be explored.

influences, and because mean fitness is increased. In fact, it is possible to think of the attraction between clines described above as an effect of asymmetrical gene flow created by the removal of alleles on one side of the cline due to their association with alleles at the other locus (cf. Barton and Hewitt 1985, p. 116). Therefore, the one-allele and two-allele coupling processes are closely related.

Adaptive Coupling with Further Evolution of a Barrier Effect. Felsenstein (1981) also considered whether the assortative mating allele A would spread when initially rare. This introduces an additional process: not only do the two barrier effects become coincident but one of them evolves. The overall barrier is enhanced by both of these processes, and they are, at least in this simple model, inseparable because the change in allele frequency at the $\mathrm{A}$ locus is dependent on $\mathrm{LD}$ with the $\mathrm{B}$ and $\mathrm{C}$ loci; evolution of the $\mathrm{A}$ locus is driven entirely by indirect selection. Barton and de Cara (2009) considered a generalization of the Felsenstein (1981) model. They showed that a prezygotic barrier effect would couple with an indefinite number of incompatibilities. In this specific case, unlike most of the models they analyzed, they also showed that the allele frequencies at a locus causing assortative mating would tend toward 0.5 from any starting frequency: in effect, assortative mating would be enhanced as well as coupled to the incompatibilities. The set of processes of this type falls within adap- tive coupling because a component of selection arises from the interaction between barrier effects. However, coupling is now accompanied by an increase in one barrier effect, rather than two existing barrier effects simply becoming coincident (fig. $1 B$, II).

The Felsenstein (1981) result and its extension are consistent with other models of reinforcement that show the evolution of prezygotic isolation given the existence of a postzygotic barrier effect (Servedio and Noor 2003; Servedio 2009; fig. $1 B$, II.i; fig. 3, case 3a). These models apply to other forms of prezygotic isolation, such as two-allele barrier effects of habitat choice or gamete recognition. Versions of reinforcement models include the evolution of one-allele prezygotic barrier effects (fig. 3, case 4a). The sexual selection model of van Doorn et al. (2009) is also similar: a one-allele barrier effect of female preference for high-quality males becomes associated with and enhanced by a barrier effect of local adaptation through its impact on a male signal trait. All of these scenarios share the key features of adaptive coupling with further evolution of barrier effects: selection simultaneously favors coincidence of two barrier effects and an increase in one of them.

Models of reinforcement have explored extensively the conditions that favor or oppose the evolution of stronger prezygotic isolation in response to postzygotic barrier effects. Reinforcement is more likely - and likely to generate 
a stronger overall barrier-where the effects of barrier loci on prezygotic isolation are strong, where hybridization is common and the cost is high, and where the opposing forces of gene flow and recombination are weak (Servedio and Noor 2003; Coyne and Orr 2004; Barton and de Cara 2009; Servedio 2009; Smadja and Butlin 2011). The dependence of reinforcement on costs means that it can be selflimiting: evolution of one new barrier effect can prevent the evolution of another (Yukilevich and True 2006). Models typically concentrate on cases where no direct selection acts on the trait or traits underlying prezygotic isolation, in order to focus on the indirect selection arising through LD with existing barrier loci. However, this is a modeling strategy to isolate the reinforcement effect. In the real world, other sources of selection on the loci or traits involved may oppose reinforcement or favor evolution of barrier loci or traits, and these direct components of selection can have major impacts on coupling and evolution of barrier effects (Servedio et al. 2011; Smadja and Butlin 2011).

The balance of these effects leads to well-known predictions (table 1). For one-allele models, a single allele that causes assortative mating may automatically form genetic associations that lead to it being favored by indirect selection in all parts of its range (Servedio 2000). These associations with the high-fitness trait alleles in each population form simply because these trait alleles occur at a high frequency. In oneallele systems that generate such unopposed selection, reinforcement will always occur, in contrast to two-allele models where divergence between populations and LD between specific pre- and postzygotic barrier alleles are opposed by both gene flow and recombination (although this distinction breaks down as gene flow becomes more asymmetric; Servedio 2000). Where the indirect selection resulting from association between a prezygotic barrier effect and a postzygotic barrier effect is opposed by direct selection-for example, due to costs of assortative mating - reinforcement is easily prevented. Where indirect selection is supplemented by direct selection, reinforcement is much more likely (e.g., Servedio 2001). This can happen when divergence in male signal traits is favored by divergent female preferences (e.g., Liou and Price 1994). In such cases of signal-preference coevolution, assortative mating helps to build and maintain LD between barrier loci. Direct selection can also favor divergence when the prezygotic barrier trait is a multiple-effect trait, such as a wing pattern that functions in mimicry as well as being a sexual signal (Merrill et al. 2011; reviewed in Servedio et al. 2011; Smadja and Butlin 2011) or when loci contributing to assortative mating also contribute to behavioral sterility (e.g., Naisbit et al. 2001). In these cases, the component of selection due to reinforcement is just one part of the overall selection that favors enhancement of the barrier effect (Kirkpatrick and Servedio 1999). It may be an essential part, or it may be that the new barrier effect would evolve anyway.

\section{How Does Reinforcement Fit into the Wider Context of Coupling Processes?}

In this section, we consider the relationship between the processes of coupling and reinforcement. With our definition of coupling and classification of coupling processes,

Table 1: Common factors influencing the likelihood of reinforcement

\begin{tabular}{|c|c|c|c|}
\hline & $\begin{array}{c}\text { A new barrier effect } \\
\text { is more likely to } \\
\text { evolve when }\end{array}$ & $\begin{array}{c}\text { And least likely } \\
\text { when }\end{array}$ & Notes \\
\hline Directional selection is & $\begin{array}{l}\text { Strong and divergent } \\
\text { (two-allele models)/ } \\
\text { positive (one-allele models) }\end{array}$ & Strong and stabilizing & $\ldots$ \\
\hline \multicolumn{4}{|l|}{ Indirect selection results from: } \\
\hline Opportunity for hybridization that is & Common & Rare & $\ldots$ \\
\hline A new barrier effect that is & Large & Small & $\ldots$ \\
\hline An existing barrier that is & Strong & Weak & $\ldots$ \\
\hline Linkage that is & Tight & Absent & $\begin{array}{l}\text { Dependence stronger for an } \\
\text { existing two-allele effect than } \\
\text { for an existing one-allele effect; } \\
\text { dependence weaker for new } \\
\text { one-allele barrier effect }\end{array}$ \\
\hline Gene flow is & Weak & Strong & $\begin{array}{l}\text { Little or no effect for one-allele } \\
\text { barrier effects; difference } \\
\text { declines as migration becomes } \\
\text { more asymmetrical }\end{array}$ \\
\hline
\end{tabular}


reinforcement can be considered as one type of adaptive coupling with further evolution of barrier effects, where a prezygotic barrier effect evolves as a response to a postzygotic barrier effect. However, there is little reason to separate reinforcement from other possible processes in this category, which argues for adoption of an extended view of reinforcement. We discuss open theoretical questions about the plausibility of the range of processes included under this extended view. In a later section, we will consider how coupling might be tackled empirically.

\section{Defining Reinforcement}

Reinforcement is currently defined as an "increase in premating isolation in response to selection against hybridisation" (Servedio and Noor 2003). The idea goes back to Wallace (1889), although the term is much younger (Blair 1955), and it has had a turbulent history (Howard 1993; Butlin 1995; Servedio and Noor 2003). The changing fortunes of reinforcement are largely due to development of theory and accumulation of data (see reviews by Servedio and Noor 2003; Coyne and Orr 2004; and recent work by, e.g., Lemmon and Lemmon 2010; Yukilevich 2012; Smadja et al. 2015), but they have also been influenced by redefinition of the term, as with other ideas in speciation biology (Harrison 2012). The current definition originates from Dobzhansky's (1937) first description of the process that focused on secondary contact between populations that have evolved Dobzhansky-Muller incompatibilities, leading to the evolution of prezygotic isolation, and has progressively evolved toward a broader view of reinforcement. When defining reinforcement in its broad sense, Servedio and Noor (2003) also explicitly included postmating but prezygotic barrier effects as drivers of increased assortative mating. Servedio (2001) showed that the evolution of further prezygotic barrier effects (assortative mating) in response to existing postmating, prezygotic effects behaved very much like reinforcement driven by reduced hybrid fitness. This was, perhaps, the most significant extension of the idea, taking it beyond the exclusive realm of prezygotic barrier effects evolving in response to postzygotic barrier effects (fig. 3 , from case $3 \mathrm{a}$ alone to cases $3 \mathrm{a}$ and $3 \mathrm{~b}$ ).

Barton and de Cara (2009) explicitly restricted reinforcement to prezygotic barrier effects evolving in response to postzygotic effects (fig. 3, cases $3 \mathrm{a}$ and $4 \mathrm{a}$ ). They contrasted it with the form of coupling that they analyzed, which was implicitly restricted to two-allele barrier effects, but they emphasized the evolution of associations between barrier effects of any type (fig. 3 , case 1 ). This raises the question of whether coupling with further evolution of barrier loci or traits can occur more generally than in the specific case of prezygotic barrier effects evolving in response to postzygotic effects. Could an existing prezygotic barrier effect lead to the enhancement and coupling of additional pre- or postzygotic effects? Could a postzygotic barrier effect lead to the enhancement of further postzygotic effects? If so, would it be reasonable to call these processes reinforcement?

We propose that reinforcement should encompass, at least in principle, any situation of adaptive coupling where the existence of one barrier effect promotes the evolution of a second barrier effect, whatever the nature of these barrier effects, because there is no strong reason to draw boundaries between categories of barrier effect. Under this view, reinforcement (1) is a form (among others) of coupling and, in particular, of adaptive coupling (fig. $1 \mathrm{~B}$, II; extended view of reinforcement), (2) includes but is not limited to a class of processes where prezygotic barrier effects are enhanced and coupled to postzygotic barrier effects (fig. 1B, II.i; classical view of reinforcement), and (3) goes beyond the Servedio and Noor (2003) broad sense view of reinforcement by including any possible combination of pre- and postzygotic barrier effects. In this framework, one-allele and two-allele barrier effects may behave differently (Servedio 2000), but they can be incorporated readily into all forms of reinforcement as defined here (fig. 3, cases 3 and 4) and into all coupling processes more generally (fig. 3 , cases $1-4$ ). Since we limit coupling to processes that result in an increased overall barrier to gene exchange, this extended view of reinforcement is constrained to cases where reproductive isolation was initially incomplete and has to be distinguished from reproductive interference operating after completion of speciation (Butlin and Ritchie 2013).

\section{Plausibility of the Possible Forms of Reinforcement: Current Arguments and Future Directions}

Can we envisage plausible speciation processes involving reinforcement in sequences other than prezygotic barrier effects evolving in the presence of postzygotic effects? Clearly the answer is yes for the enhancement of prezygotic barriers in response to existing prezygotic (but postmating) barrier effects (Servedio 2001). Reinforcement of postzygotic barriers has generally been dismissed, despite the fact that the idea originated in this form (Wallace 1889; Cronin 1991; Howard 1993), except in special cases such as where competition among offspring within families can provide a benefit from early mortality of hybrid offspring or where the evolution of premating isolation is somehow constrained (Coyne 1974; Wallace 1988; Johnson and Wade 1995). However, Cronin (1991, pp. 390-391, citing unpublished work by W. D. Hamilton) argued that there is no sharp boundary at zygote formation: instead, the probability of a barrier effect evolving depends on a balance between costs and benefits.

In general, barrier effects tend to be less efficient as they occur later in the reproductive sequence (Coyne and Orr 2004). The logic of costs and benefits suggests that any barrier effect that operates earlier in the life cycle can be coupled and en- 
hanced - that is, reinforced - in response to a later-acting barrier effect. An example is provided by Neurospora fungi where there is evidence for reinforcement of an early acting postzygotic barrier-abortion of fruit bodies - in response to low hybrid fitness (Turner et al. 2010, 2011). High maternal investment, on the one hand, and strong constraints on evolution of peptide pheromones, on the other, may favor this particular barrier effect. This example fits into figure 3 , case $3 c$ (or case 4c, if fruit body abortion is a one-allele effect), an area that has not yet been explored theoretically. Natural selection does not distinguish specifically between pre- and postzygotic effects: the point at which costs outweigh benefits depends on the reproductive biology of the individual species and, of course, the range of factors that influence any form of reinforcement (table 1).

Barton and de Cara (2009) showed that existing barrier effects of two loci, each causing reduced fitness of heterozygotes, will be coupled in just the same way as a barrier effect due to assortative mating will be coupled to a barrier effect due to heterozygote disadvantage. If allele frequencies at the assortative mating locus are not initially 0.5 (in the symmetrical case studied by Barton and de Cara), they will evolve toward that point, thus increasing the prezygotic barrier effect. We do not know whether this is also true for a second locus causing heterozygote disadvantage (at least over some range of initial allele frequencies). Alternatively, a barrier may be enhanced by spread of an allele causing stronger assortment (Felsenstein 1981), following the initial establishment of coupling. A comparable effect may seem unlikely for an allele that further reduces heterozygote fitness, but this may depend, when it comes to reinforcement of prezygotic barrier effects, on other factors, especially on the strength and nature of direct selection. Some widely discussed processes that potentially contribute to speciation may be viewed as containing a component of selection that constitutes adaptive coupling with further evolution of barrier effects, as well as direct selection, and so may fit within the extended view of reinforcement but not under the classical view. We briefly discuss two scenarios in the next section.

These arguments suggest that adaptive coupling with further evolution of barrier effects should be explored theoretically and considered empirically for all possible sequences of barrier effect evolution (fig. 3): prezygotic following postzygotic (classical reinforcement), prezygotic following prezygotic, postzygotic following postzygotic, and postzygotic following prezygotic. The wide range of biological circumstances - and thus ways in which selection might operate (Cronin 1991) — needs to be taken into account. In all combinations, potential differences in behavior of one-allele and two-allele barrier effects (table 1) need to be considered. In all cases, the key theoretical issue is whether the existing barrier effect can contribute, in any way, to evo- lution of the new barrier. Indirect selection will commonly be accompanied by direct selection that might impede or enhance the evolution of a new barrier effect. Enhancement of postzygotic isolation might be impeded more frequently than enhancement of prezygotic isolation, although the common exclusion of costs of assortment or preference from classical models of reinforcement may well be unrealistic, reducing this apparent difference. Regardless of the sequence of evolution, the initial conditions (e.g., degree of divergence of the barrier to be enhanced, strength of other preexisting barriers; cf. the "starting condition" in Kirkpatrick and Ravigné 2002), the impact of gene flow, and the influence of recombination are likely to have similar importance. The outcome may be that distinguishing sequences on the basis of pre- versus postzygotic isolation is not as important for understanding adaptive coupling and further evolution of barrier effects as current views of reinforcement might suggest.

\section{Examples of Processes That Might Be Considered Adaptive Coupling with Further Evolution of Barrier Effects}

As Barton and de Cara (2009, p. 1186) briefly discuss, models of assortative mating often assume that assortment is cost free and that reduced fitness through loss of hybrid matings is compensated by increases in within-population mating. In contrast, it is implicitly assumed that loss through reduced fitness of heterozygotes cannot be compensated by increased fitness of homozygotes since the fitness of homozygotes is assumed to be fixed at its maximum. However, this assumption is relaxed if some form of frequency dependence is required to maintain polymorphism with heterozygote disadvantage (of the form pioneered by Udovic 1980), meaning that an allele contributing to an incompatibility can increase when rare, even though it reduces heterozygote fitness at equilibrium. To make this concrete, consider a phytophagous insect feeding on two host plants. A new allele, A, that enhances fitness on one host when homozygous may not spread because the fitness of the heterozygote, Aa, is reduced on both plants. Frequency dependence due to competition may make the spread of A more likely (Udovic 1980; Wilson and Turelli 1986). A prezygotic barrier between populations on the two hosts, due to habitat choice, would also make the spread of A more likely by increasing the proportion of AA homozygotes and their chances of being on the host where they have high fitness. Since A would spread only on one host, this would result in coupling of a new postzygotic barrier effect to the existing barrier (a potential example of case $3 \mathrm{~d}$ in fig. 3 ). A component of direct selection favoring the evolution of the new barrier effect may be essential. Empirically, we know that coincident barriers occur in this way (e.g., in the leaf beetle, Lochmaea capreae; Soudi et al. 2016), but typically we do not know the sequence of events, especially the cause of the coupling. The outstanding theoretical question is whether 
the probability of spread of such an allele can be enhanced, or the equilibrium can be altered, by a preexisting barrier effect. If so, this could be considered a form of reinforcement that increases a postzygotic barrier effect given a preexisting barrier that may be either pre- or postzygotic.

When a two-allele barrier effect exists between two populations, it generates a genomically localized reduction in effective migration around the barrier loci involved (Barton and Bengtsson 1986). This is true for both pre- and postzygotic barrier effects. As a result, a new mutation at a closely linked locus under divergent selection has an increased probability of spreading and is likely to reach a higher equilibrium frequency (Feder and Nosil 2010; Yeaman and Whitlock 2011). This is sometimes called "divergence hitchhiking," but we avoid this term because it fails to distinguish between the effect of a locally advantageous allele on neighboring loci during its spread and its subsequent barrier effect. The new mutation also has a lower probability of stochastic loss, which may have a greater influence on its long-term contribution to differentiation between populations (Rafajlovic et al. 2016). If it does spread and persist, the new allele increases the overall barrier and is coupled with the original barrier effect. Reduced effective migration comes about because of an indirect component of selection arising through LD. Therefore, this process falls into our category of adaptive coupling with further evolution of barrier effects (= extended view of reinforcement). Models of the process have focused on the impact of divergence at loci involved in local adaptation on the evolution of linked barrier loci that are also under direct divergent selection (Flaxman et al. 2013, 2014). However, this is not necessary: any barrier locus that decreases effective migration potentially operates in the same way, and new mutations, generating additional barrier effects, need not be under divergent selection. Although these models focus on the evolution of LD between barrier effects that is dependent on physical linkage, they are not fundamentally different from classical models of reinforcement in which some loci contribute to postzygotic isolation, while others contribute to assortative mating, and the factors affecting evolution of stronger barriers (table 1) are actually rather similar in these apparently very different models. Importantly, they suggest that any type of barrier effect (pre- or postzygotic) can evolve and become coupled with an existing barrier effect (itself pre- or postzygotic) under this process (fig. 3 , cases $3 a-3 d$ and $4 a-4 d$ ).

\section{How Can the Role of Coupling in Speciation Be Tackled Empirically? Current Knowledge and Future Directions}

Empirically, the challenge of determining the role of coupling in speciation can be broken down into two components. The first is to document the pattern of coincidence, or lack of coincidence, of barrier effects at different stages in speciation, where the overall barrier ranges from very weak to near complete reproductive isolation. The second is to distinguish among the types of coupling process that result in coincidence and to determine the factors that make them more likely to contribute.

\section{Evidencing Patterns of Coincidence}

In hybrid zones, there is good evidence for coincidence of barrier effects and its impact on the overall barrier to gene exchange from the observation of genome-wide stepped clines in some examples (e.g., Szymura and Barton 1986, 1991; Gay et al. 2008), in contrast to scattered clines and a weak barrier to gene flow in others (e.g., Shuker et al. 2005). However, where a strong barrier influences the whole genome (as in Bombina; Szymura and Barton 1991), it is hard to separate the underlying barrier effects and the loci responsible since all clines become stepped and concordant. Intermediate cases also exist, where some clines are stepped and others are not, reflecting underlying variation in both barrier strength, coincidence, and LD among loci. This is true of the mouse hybrid zone (e.g., Macholán et al. 2007), and it opens the opportunity to identify individual barrier effects, the traits and loci on which they are based, and the extent of coupling between them.

Outside the hybrid zone context, coincidence of barrier effects has rarely been documented explicitly. Where the overall barrier to gene flow is strong (but not complete), multiple barrier effects are typically found to contribute (Coyne and Orr 2004). Studies that dissect the different contributions (e.g., Scopece et al. 2013) are important, and more are needed. However, it is also important to study weaker overall barriers-or even to compare populations with no known barrier a priori-in order to document the pattern of origin of individual barrier effects and, especially, to ask whether initial stages of divergence often include noncoincident barrier effects, as in the Ostrinia example mentioned above. Some studies have examined the increase in barrier effects with geographic (e.g., Tilley et al. 1990) or ecological (Nosil et al. 2009) distance, or in preplanned comparisons that reflect population history (Tregenza et al. 2000). Crosses between populations sometimes reveal unexpected and strong barrier effects (e.g., Jennings et al. 2014). More surveys like these are needed, preferably measuring overall barriers and dissecting the component barrier effects. Critically, one-allele and twoallele barrier effects need to be distinguished.

\section{Distinguishing among Coupling Processes}

Given cases of both coincident and noncoincident barrier effects, how can the different possible origins of coincidence be distinguished? Hybrid zones - or, more generally, tran- 
sects across boundaries between divergent populationscan provide important clues. In sticklebacks, Vines et al. (2016) used the coincidence of clines to test the relative roles of direct and indirect selection on different traits and loci. They found that direct selection maintains distinct cline positions at some loci, while close concordance in slope for colocated clines suggests strong LD and indirect selection (i.e., coupling) at others, although surprisingly they did not detect stepped clines. Only when loci are linked to phenotypes will it be possible to infer whether this coupling is a by-product of divergent selection across coincident environmental boundaries, adaptive coupling of overlapping clines, or perhaps reinforcement. This study nicely shows how predictions on cline shape and position can help to distinguish the effects of direct and indirect selection on barrier loci and the existence of coupling among barrier loci but also underlines the need to extend theoretical work to envisage all possible predicted patterns generated by coupling in hybrid zones.

Away from the hybrid zone context, signals of coupling for two-allele barrier effects should still be present in patterns of linkage disequilibrium. Now that genome-wide data can be gathered and new tools are becoming available that help to access complex patterns of LD (e.g., Baird 2015; Kemppainen et al. 2015), there are important opportunities to make progress in this direction. However, it will be critical to link genetic patterns to an understanding of phenotypes and their role in reproductive isolation (as emphasized by Seehausen et al. 2014) in order to distinguish coupling processes. This will be especially critical for one-allele barrier effects where any LD signature is expected to be transient. Here, the classical approach of comparing allopatric and sympatric populations - to test the prediction that adaptive coupling requires gene flow-may be one of the few ways forward.

Recent theoretical and empirical research has addressed the genome-wide patterns of differentiation between diverging taxa and the mechanisms generating them. This work may help to answer key questions: What are the dynamics of genomic coupling during the progression toward speciation? What is the role of chromosomal linkage in these dynamics? Can we empirically tease apart by-product versus adaptive coupling? Whether adaptive coupling occurs is expected to depend on the genetic architecture, including the number of segregating barrier loci, the strength of selection on each locus, and the rate of recombination (Felsenstein 1981; Smadja and Butlin 2011; Seehausen et al. 2014). The combination of these factors will shape the patterns of genomic differentiation and determine how coupling progresses as speciation unfolds (Feder et al. 2012a; Flaxman et al. 2013, 2014), with the possibility of an abrupt transition in coupling from weak local genomic barriers around individual loci to a strong genome-wide barrier (i.e., genome-wide congealing; Flaxman et al. 2013; Feder et al. 2014; Nosil et al. 2017) corresponding to the critical value of the coupling coefficient of Barton (1983), at which overall selection outweighs the impact of recombination. In addition to multilocus clinal analyses mentioned above, we are starting to see evidence for the expected disjunction in genome-wide comparisons across multiple levels of divergence (Riesch et al. 2017). If there are transitions between phases on the route to speciation, then coupling is likely to be a key process in what Riesch and colleagues call "alignment of multifaceted aspects of differentiation" (p. 1).

Although coupling among barrier loci does not require physical linkage (Barton and de Cara 2009; Flaxman et al. 2013, 2014), genomic architectures that eliminate or decrease recombination (from pleiotropy to close physical linkage or large regions of reduced recombination) are expected to facilitate coupling and, hence, speciation (Kirkpatrick and Barton 2006; Yeaman and Whitlock 2011; Ortiz-Barrientos et al. 2016). In agreement with this, cases have been documented of pleiotropy (reviewed in Servedio et al. 2011) or of barrier loci falling in regions of reduced recombination (reviewed in Hoffmann and Rieseberg 2008; Faria and Navarro 2010). There is also increasing evidence for clustered genetic architectures of differentiation (reviewed in Seehausen et al. 2014; Wolf and Ellegren 2017) and reproductive isolation (e.g., Merrill et al. 2011; Smadja et al. 2012; Hermann et al. 2013). Theoretical models have started to explore some possible mechanisms generating or favoring these clustered architectures (i.e., divergence hitchhiking [Feder et al. 2012b; Flaxman et al. 2013, 2014; Yeaman et al. 2016]; chromosomal rearrangements [Yeaman 2013]; erosion from secondary contact [Yeaman et al. 2016]; stochastic loss and gain of local genomic differentiation [Rafajlovic et al. 2016]), but testing these scenarios with empirical data remains challenging.

To understand how coupling contributes to the overall barrier to gene exchange over the course of a speciation event requires the reconstruction of the sequence of events, as others have emphasized for individual barrier loci (e.g., Nosil and Schluter 2011). This reconstruction is difficult to achieve. Gathering information on the history of divergence and gene flow is crucial (Payseur and Rieseberg 2016) to determine whether coupling has occurred as a by-product or as an adaptive response and to find the causal link between the evolution of two barrier effects. However, comparative analyses may also represent an important way forward. Since the temporal progression of speciation can only rarely be studied in real time, a promising direction is to compare populations at different stages of divergence in a system (Seehausen et al. 2014; Shaw and Mullen 2014; Riesch et al. 2017). This approach can help to reconstruct how genomic differentiation and coupling among barrier effects progress during speciation, assess whether the evolution of coupling and genome congealing (Barton 1983; Flaxman et al. 2013) is gradual, and test the role 
of chromosomal linkage and recombination rate variation in the evolution of coupling (e.g., Gagnaire et al. 2013; Nadeau et al. 2013; Burri et al. 2015; Feulner et al. 2015). Comparisons among examples with different overall barriers and different combinations of barrier effects, as well as comparative analyses of replicated and independent events of contact in a given system can also help this reconstruction (e.g., Nadeau et al. 2014; Vijay et al. 2017). In general, it will be important to identify more systems offering multiple hybrid zones to compare situations where coupling may not be at the same stage across the distribution range (e.g., in common voles [Beysard and Heckel 2014], Hyla frogs [Dufresnes et al. 2015], or green toads [Dufresnes et al. 2014]). Combining genomic analysis of such systems with analysis of phenotypes and the types of barrier effects (one allele vs. two allele) is the most likely route toward understanding of coupling processes.

\section{Concluding Remarks}

Most cases of speciation require two types of process: the evolution of barrier effects and the coupling of those effects. Coincidence of barrier effects can be a by-product of other processes, but it can also be adaptive. Evolution of barrier effects and their coupling may be independent, or they may be intimately interconnected in the category that we call adaptive coupling with further evolution of barrier loci/traits. This category is equivalent to an extended view of reinforcement and contains the classical case where existing postzygotic barrier effects cause the evolution of prezygotic barriers. Therefore, to understand speciation, it is not sufficient to document individual barrier effects and their origins. Empiricists should not take for granted the coincidence of barrier effects but should test for coupling and try to find ways to distinguish among the different processes by which coupling might have occurred. This requires systematic documentation of all barriers separating populations, determining their genetic basis, and measuring their associations. New approaches may be needed to determine the sequence of barrier appearance and the roles of by-product or adaptive processes in bringing barriers together.

In attempting to distinguish between the origin and coupling of barriers, and to categorize coupling processes, we do not wish to define modes of speciation. On the contrary, most cases of speciation are likely to involve multiple stages. For example, divergent selection for local adaptation might create an initial barrier effect. This might be coupled with intrinsic incompatibilities as a by-product of coincidence between ecological discontinuities and partial physical barriers to gene flow or periods of allopatry. The relatively strong barrier generated by this coupling may result in the evolution of prezygotic barrier effects by classical reinforcement as well as facilitating further local adaptation by a process that includes a component of indirect selection on new postzygotic barrier effects. Speciation may then be completed by further coupling to intrinsic incompatibilities during range contraction and expansion. An alternative scenario might begin with a one-allele barrier effect of increased imprinting on the natal habitat. This could facilitate subsequent evolution of local adaptation across habitat boundaries resulting in reduced fitness of migrants and hybrids. In turn, this might result in reinforcement via a one-allele modifier of the habitat preference. The resulting discontinuity between populations in different habitats would then trap barriers due to intrinsic incompatibility. Clearly, one can envisage many possible sequences. The changes in distribution, population size, and opportunities for gene exchange that invariably occur during speciation (Abbott et al. 2013) will influence how these scenarios play out. Most importantly, adaptive coupling processes can only occur when gene exchange is possible.

We also wish to emphasize that the component of selection due to coupling may not act alone. It is often convenient to minimize the impact of direct selection pressures in models in order to see the relatively weak effects of indirect selection. However, barrier loci and traits influence critical processes for survival and reproduction; otherwise they would be unlikely to generate significant barrier effects. Therefore, we should expect that they are typically under direct selection, which may either favor or oppose the evolution of barrier effects. We need more theoretical work that incorporates these other components of selection. As we speculated above, this may help to demonstrate commonalities between different classes of coupling that fall within the extended view of reinforcement. We also need to try to separate the components of selection empirically, however difficult this may be (Kirkpatrick and Servedio 1999).

Here, we wish to emphasize that understanding of the evolution of individual barrier effects is not sufficient: we also need to understand how and why barrier effects come to be coincident and whether the evolution of a given barrier effect was dependent on preexisting barriers. We hope that the distinctions we make here between evolution of barrier effects and their coupling - and between different categories of coupling process - will help to guide this empirical effort along with theoretical developments in speciation research. Servedio and Noor (2003) argued that the true importance of reinforcement in speciation was unlikely to be estimated reliably until all possible ways in which it could occur were addressed both in theory and empirically. We agree and extend their argument to coupling processes in general.

\section{Acknowledgments}

We are very grateful to the Stellenbosch Institute for Advanced Study (STIAS) for the opportunity to work together on this article in a highly stimulating environment and to Terry Robinson for initiating our contact with STIAS and 
making our time in South Africa so pleasant and productive. We thank Anja Westram, Mike Ritchie, Isobel Eyres, Takeshi Kawakami, and Mohamed Noor's research group for helpful comments on a draft of the manuscript. R.K.B. acknowledges support from the Natural Environment Research Council and the European Research Council, and
C.M.S. acknowledges support from the Agence Nationale pour la Recherche. This is publication ISEM 2017-187. We dedicate this article to the memory of Rick Harrison, who was a friend and an inspiration to us both. He may not have liked what we have to say, but it would certainly have been a pleasure to have discussed it with him.

\section{APPENDIX}

Table A1: Glossary

\begin{tabular}{|c|c|}
\hline Term & Definition \\
\hline Adaptive coupling & Class of coupling processes, where coincidence of barrier effects is favored by selection \\
\hline Barrier effect & $\begin{array}{l}\text { Contribution that a barrier locus or trait, or some combination of barrier loci or } \\
\text { traits, makes to overall isolation }\end{array}$ \\
\hline Barrier locus & Locus that contributes to a barrier to gene exchange \\
\hline Barrier trait & Trait that contributes to a barrier to gene exchange \\
\hline Barrier to gene flow & Component of reproductive isolation between populations \\
\hline By-product coupling & Class of coupling processes, where coincidence evolves but is not itself favored by selection \\
\hline Coupling & $\begin{array}{l}\text { Set of processes that generate coincidence of barrier effects, resulting in a stronger } \\
\text { overall barrier to gene flow }\end{array}$ \\
\hline One-allele barrier effect & $\begin{array}{l}\text { Barrier effect caused by the spread of a single allele at a barrier locus, or evolution of a barrier trait in the } \\
\text { same direction, in both of two populations }\end{array}$ \\
\hline Overall barrier & Combined effect on gene flow of all components of reproductive isolation \\
\hline Reinforcement & $\begin{array}{l}\text { Increase in premating isolation in response to selection against hybridization, but we propose an extended } \\
\text { definition in which reinforcement is the origin or enhancement of any barrier effect in } \\
\text { response to a preexisting barrier; reinforcement is then equivalent to our category of adaptive } \\
\text { coupling, with further evolution of barrier effects }\end{array}$ \\
\hline Speciation & $\begin{array}{l}\text { Origin of new species by the splitting of existing species, equivalent to the evolution of reproductive } \\
\text { isolation (speciation is complete when reproductive isolation is complete; here we consider only } \\
\text { species with obligatory sexual reproduction) }\end{array}$ \\
\hline Two-allele barrier effect & $\begin{array}{l}\text { Barrier effect that depends on the spread of different alleles at one or more barrier loci, or divergence } \\
\text { in one or more barrier traits between two populations }\end{array}$ \\
\hline
\end{tabular}

\section{Literature Cited}

Abbott, R., D. Albach, S. Ansell, J. W. Arntzen, S. J. E. Baird, N. Bierne, J. Boughman, et al. 2013. Hybridization and speciation. Journal of Evolutionary Biology 26:229-246.

Baack, E., M. C. Melo, L. H. Rieseberg, and D. Ortiz-Barrientos. 2015. The origins of reproductive isolation in plants. New Phytologist 207:968-984.

Baird, S. J. E. 2015. Exploring linkage disequilibrium. Molecular Ecology Resources 15:1017-1019.

Bank, C., R. Burger, and J. Hermisson. 2012. The limits to parapatric speciation: Dobzhansky-Muller incompatibilities in a continentisland model. Genetics 191:845-863.

Barton, N. H. 1983. Multilocus clines. Evolution 37:454-471. . 2013. Does hybridization influence speciation? Journal of Evolutionary Biology 26:267-269.

Barton, N. H., and B. O. Bengtsson. 1986. The barrier to genetic exchange between hybridizing populations. Heredity 57:357-376.

Barton, N. H., and M. A. R. de Cara. 2009. The evolution of strong reproductive isolation. Evolution 63:1171-1190.
Barton, N. H., and K. S. Gale. 1993. Genetic analysis of hybrid zones. Pages 13-45 in R. G. Harrison, ed. Hybrid zones and the evolutionary process. Oxford University Press, New York.

Barton, N. H., and G. M. Hewitt. 1985. Analysis of hybrid zones. Annual Review of Ecology and Systematics 16:113-148.

Beltman, J. B., and J. A. J. Metz. 2005. Speciation: more likely through a genetic or through a learned habitat preference? Proceedings of the Royal Society B 272:1455-1463.

Beysard, M., and G. Heckel. 2014. Structure and dynamics of hybrid zones at different stages of speciation in the common vole (Microtus arvalis). Molecular Ecology 23:673-687.

Bierne, N., J. Welch, E. Loire, F. Bonhomme, and P. David. 2011. The coupling hypothesis: why genome scans may fail to map local adaptation genes. Molecular Ecology 20:2044-2072.

Blair, Frank W. 1955. Mating call and stage of speciation in the Microhyla olivacea-M. carolinensis complex. Evolution 9:469480.

Bolnick, D. I., and B. M. Fitzpatrick. 2007. Sympatric speciation: models and empirical evidence. Annual Review of Ecology, Evolution and Systematics 38:459-487. 
Burri, R., A. Nater, T. Kawakami, C. F. Mugal, P. I. Olason, L. Smeds, A. Suh, et al. 2015. Linked selection and recombination rate variation drive the evolution of the genomic landscape of differentiation across the speciation continuum of Ficedula flycatchers. Genome Research 25:1656-1665.

Butlin, R. K. 1987. Speciation by reinforcement. Trends in Ecology and Evolution 2:8-13.

- 1995. Reinforcement — an idea evolving. Trends in Ecology and Evolution 10:432-434.

Butlin, R. K., and M. G. Ritchie. 2013. Pulling together or pulling apart: hybridization in theory and practice. Journal of Evolutionary Biology 26:294-298.

Cain, M. L., V. Andreasen, and D. J. Howard. 1999. Reinforcing selection is effective under a relatively broad set of conditions in a mosaic hybrid zone. Evolution 53:1343-1353.

Cooley, J. R., C. Simon, and D. C. Marshall. 2003. Temporal separation and speciation in periodical cicadas. Bioscience 53:151-157.

Coyne, J. A. 1974. Evolutionary origin of hybrid incompatibility. Evolution 28:505-506.

Coyne, J. A., and H. A. Orr. 2004. Speciation. Sinauer, Sunderland, MA.

Cronin, H. 1991. The ant and the peacock: altruism and sexual selection from Darwin to today. Cambridge University Press, Cambridge.

Dobzhansky, T. 1937. Genetics and the origins of species. Columbia University Press, New York.

Dopman, E. B., P. S. Robbins, and A. Seaman. 2010. Components of reproductive isolation between North American pheromone strains of the European corn borer. Evolution 64:881-902.

Dufresnes, C., L. Bonato, N. Novarini, C. Betto-Colliard, N. Perrin, and M. Stoeck. 2014. Inferring the degree of incipient speciation in secondary contact zones of closely related lineages of Palearctic green toads (Bufo viridis subgroup). Heredity 113:9-20.

Dufresnes, C., A. Brelsford, J. Crnobrnja-Isailovic, N. Tzankov, P. L. Nicolas, and N. Perrin. 2015. Timeframe of speciation inferred from secondary contact zones in the European tree frog radiation (Hyla arborea group). BMC Evolutionary Biology 15:155.

Faria, R., and A. Navarro. 2010. Chromosomal speciation revisited: rearranging theory with pieces of evidence. Trends in Ecology and Evolution 25:660-669.

Feder, J. L., S. P. Egan, and P. Nosil. 2012a. The genomics of speciationwith-gene-flow. Trends in Genetics 28:342-350.

Feder, J. L., R. Gejji, S. Yeaman, and P. Nosil. 2012b. Establishment of new mutations under divergence and genomic hitchhiking. Philosophical Transactions of the Royal Society B 367:461-474.

Feder, J. L., and P. Nosil. 2010. The efficacy of divergence hitchhiking in generating genomic islands during ecological speciation. Evolution 64:1729-1747.

Feder, J. L., P. Nosil, A. C. Wacholder, S. P. Egan, S. H. Berlocher, and S. M. Flaxman. 2014. Genome-wide congealing and rapid transitions across the speciation continuum during speciation with gene flow. Journal of Heredity 105:810-820.

Felsenstein, J. 1981. Skepticism towards Santa Rosalia, or why are there so few kinds of animals? Evolution 35:124-138.

Feulner, P. G. D., F. J. J. Chain, M. Panchal, Y. Huang, C. Eizaguirre, M. Kalbe, T. L. Lenz, et al. 2015. Genomics of divergence along a continuum of parapatric population differentiation. PLoS Genetics 11:e1005414.

Flaxman, S. M., J. L. Feder, and P. Nosil. 2013. Genetic hitchhiking and the dynamic buildup of genomic divergence during speciation with gene flow. Evolution 67:2577-2591.
Flaxman, S. M., A. C. Wacholder, J. L. Feder, and P. Nosil. 2014 Theoretical models of the influence of genomic architecture on the dynamics of speciation. Molecular Ecology 23:4074-4088.

Gagnaire, P.-A., S. A. Pavey, E. Normandeau, and L. Bernatchez. 2013. The genetic architecture of reproductive isolation during speciation-with-gene-flow in lake whitefish species pairs assessed by RAD sequencing. Evolution 67:2483-2497.

Gay, L., P.-A. Crochet, D. A. Bell, and T. Lenormand. 2008. Comparing clines on molecular and phenotypic traits in hybrid zones: a window on tension zone models. Evolution 62:2789-2806.

Gittenberger, E., T. D. Hamann, and T. Asami. 2012. Chiral speciation in terrestrial pulmonate snails. PLoS ONE 7:e34005.

Harrison, R. G. 2012. The language of speciation. Evolution 66:36433657.

Hermann, K., U. Klahre, M. Moser, H. Sheehan, T. Mandel, and C. Kuhlemeier. 2013. Tight genetic linkage of prezygotic barrier loci creates a multifunctional speciation island in petunia. Current Biology 23:873-877.

Hewitt, G. M. 1989. The subdivision of species by hybrid zones. Pages 85-110 in D. Otte and J. A. Endler, eds. Speciation and its consequences. Sinauer, Sunderland, MA.

. 1996. Some genetic consequences of ice ages, and their role in divergence and speciation. Biological Journal of the Linnean Society 58:247-276.

Hoffmann, A. A., and L. H. Rieseberg. 2008. Revisiting the impact of inversions in evolution: from population genetic markers to drivers of adaptive shifts and speciation? Annual Review of Ecology Evolution and Systematics 39:21-42.

Howard, D. J. 1993. Reinforcement: origin, dynamics and fate of an evolutionary hypothesis. Pages 46-69 in R. G. Harrison, ed. Hybrid zones and the evolutionary process. Oxford University Press, New York.

Jennings, J. H., R. R. Snook, and A. Hoikkala. 2014. Reproductive isolation among allopatric Drosophila montana populations. Evolution 68:3095-3108.

Johnson, N., and M. Wade. 1995. Conditions for soft selection favoring the evolution of hybrid inviability. Journal of Theoretical Biology 176:493-499.

Kelly, J. K., and M. A. F. Noor. 1996. Speciation by reinforcement: a model derived from studies of Drosophila. Genetics 143:1485-1497.

Kemppainen, P., C. G. Knight, D. K. Sarma, T. Hlaing, A. Prakash, Y. N. M. Maung, P. Somboon, J. Mahanta, and C. Walton. 2015. Linkage disequilibrium network analysis (LDna) gives a global view of chromosomal inversions, local adaptation and geographic structure. Molecular Ecology Resources 15:1031-1045.

Kirkpatrick, M. 2000. Reinforcement and divergence under assortative mating. Proceedings of the Royal Society B 267:1649-1655.

Kirkpatrick, M., and N. Barton. 2006. Chromosome inversions, local adaptation and speciation. Genetics 173:419-434.

Kirkpatrick, M., and V. Ravigné. 2002. Speciation by natural and sexual selection: models and experiments. American Naturalist 159(suppl.):S22-S35.

Kirkpatrick, M., and M. R. Servedio. 1999. The reinforcement of mating preferences on an island. Genetics 151:865-884.

Lemmon, E. M., and A. R. Lemmon. 2010. Reinforcement in chorus frogs: lifetime fitness estimates including intrinsic natural selection and sexual selection against hybrids. Evolution 64:1748-1761.

Limborg, M. T., R. K. Waples, J. E. Seeb, and L. W. Seeb. 2014. Temporally isolated lineages of pink salmon reveal unique signatures of selection on distinct pools of standing genetic variation. Journal of Heredity 105:741-751. 
Liou, L. W., and T. D. Price. 1994. Speciation by reinforcement of premating isolation. Evolution 48:1451-1459.

Macholán, M., P. Munclinger, M. Sugerkova, P. Dufková, B. Bímová, E. Bozikova, J. Zima, and J. Piálek. 2007. Genetic analysis of autosomal and X-linked markers across a mouse hybrid zone. Evolution 61:746-771.

Marques, D. A., K. Lucek, J. I. Meier, S. Mwaiko, C. E. Wagner, L. Excoffier, and O. Seehausen. 2016. Genomics of rapid incipient speciation in sympatric threespine stickleback. PLoS Genetics 12: e1005887.

Maynard Smith, J. 1966. Sympatric speciation. American Naturalist 100:637-650.

Mayr, E. 1963. Animal species and evolution. Harvard University Press, Cambridge, MA.

Merrill, R. M., B. Van Schooten, J. A. Scott, and C. D. Jiggins. 2011 Pervasive genetic associations between traits causing reproductive isolation in Heliconius butterflies. Proceedings of the Royal Society B 278:511-518.

Michel, A. P., S. Sim, T. H. Q. Powell, M. S. Taylor, P. Nosil, and J. L. Feder. 2010. Widespread genomic divergence during sympatric speciation. Proceedings of the National Academy of Sciences of the USA 107:9724-9729.

Nadeau, N. J., S. H. Martin, K. M. Kozak, C. Salazar, K. K Dasmahapatra, J. W. Davey, S. W. Baxter, et al. 2013. Genomewide patterns of divergence and gene flow across a butterfly radiation. Molecular Ecology 22:814-826.

Nadeau, N. J., M. Ruiz, P. Salazar, B. Counterman, J. A. Medina, H. Ortiz-Zuazaga, A. Morrison, et al. 2014. Population genomics of parallel hybrid zones in the mimetic butterflies, $H$. melpomene and H. erato. Genome Research 24:1316-1333.

Naisbit, R. E., C. D. Jiggins, and J. Mallet. 2001. Disruptive sexual selection against hybrids contributes to speciation between Heliconius cydno and Heliconius melpomene. Proceedings of the Royal Society B 268:1849-1854.

Nosil, P. 2012. Ecological speciation: Oxford series in ecology and evolution. Oxford University Press, Oxford.

Nosil, P., J. Feder, S. M. Flaxman, and Z. Gompert. 2017. Tipping points in the dynamics of speciation. Nature Ecology and Evolution 1:0001.

Nosil, P., D. J. Funk, and D. Ortiz-Barrientos. 2009. Divergent selection and heterogeneous genomic divergence. Molecular Ecology 18:375-402.

Nosil, P., and D. Schluter. 2011. The genes underlying the process of speciation. Trends in Ecology and Evolution 26:160-167.

Orsucci, M., P. Audiot, A. Pommier, C. Raynaud, B. Ramora, A. Zanetto, D. Bourguet, and R. Streiff. 2016. Host specialization involving attraction, avoidance and performance, in two phytophagous moth species. Journal of Evolutionary Biology 29:114-125.

Ortiz-Barrientos, D., J. Engelstaedter, and L. H. Rieseberg. 2016. Recombination rate evolution and the origin of species. Trends in Ecology and Evolution 31:226-236.

Payseur, B. A., and L. H. Rieseberg. 2016. A genomic perspective on hybridization and speciation. Molecular Ecology 25:2337-2360.

Rafajlovic, M., A. Emanuelson, K. Johannesson, R. K. Butlin, and B. Mehlig. 2016. A universal mechanism generating clusters of differentiated loci during divergence-with-migration. Evolution 70:1609-1621.

Rice, W. R., and E. E. Hostert. 1993. Laboratory experiments on speciation - what have we learned in 40 years. Evolution 47:1637-1653.

Riesch, R., M. Muschick, D. Lindtke, R. Villoutreix, A. A. Comeault, T. E. Farkas, K. Lucek, et al. 2017. Transitions between phases of genomic differentiation during stick-insect speciation. Nature Ecology and Evolution 1:0082.

Rundle, H. D., and P. Nosil. 2005. Ecological speciation. Ecology Letters 8:336-352.

Sanderson, N. 1989. Can gene flow prevent reinforcement? Evolution 43:1223-1235.

Savolainen, V., M. C. Anstett, C. Lexer, I. Hutton, J. J. Clarkson, M. V. Norup, M. P. Powell, D. Springate, N. Salamin, and W. J. Baker. 2006. Sympatric speciation in palms on an oceanic island. Nature 441:210-213.

Schluter, D. 2009. Evidence for ecological speciation and its alternative. Science 323:737-741.

Scopece, G., A. Croce, C. Lexer, and S. Cozzolino. 2013. Components of reproductive isolation between Orchis mascula and Orchis pauciflora. Evolution 67:2083-2093.

Searle, J. B. 1993. Chromosomal hybrid zones in eutherian mammals. Pages 309-353 in R. G. Harrison, ed. Hybrid zones and the evolutionary process. Oxford University Press, New York.

Seehausen, O. 2013. Conditions when hybridization might predispose populations for adaptive radiation. Journal of Evolutionary Biology 26:279-281.

Seehausen, O., R. K. Butlin, I. Keller, C. E. Wagner, J. W. Boughman, P. A. Hohenlohe, C. L. Peichel, et al. 2014. Genomics and the origin of species. Nature Reviews Genetics 15:176-192.

Seehausen, O., and C. E. Wagner. 2014. Speciation in freshwater fishes. Annual Review of Ecology, Evolution, and Systematics 45:621-651.

Servedio, M. R. 2000. Reinforcement and the genetics of nonrandom mating. Evolution 54:21-29.

- 2001. Beyond reinforcement: the evolution of premating isolation by direct selection on preferences and postmating, prezygotic incompatibilities. Evolution 55:1909-1920.

- 2009. The role of linkage disequilibrium in the evolution of premating isolation. Heredity 102:51-56.

Servedio, M. R., and M. Kirkpatrick. 1997. The effects of gene flow on reinforcement. Evolution 51:1764-1772.

Servedio, M. R., and M. A. F. Noor. 2003. The role of reinforcement in speciation: theory and data. Annual Review of Ecology, Evolution and Systematics 34:339-364.

Servedio, M. R., G. S. Van Doorn, M. Kopp, A. M. Frame, and P. Nosil. 2011. Magic traits in speciation: "magic" but not rare? Trends in Ecology and Evolution 26:389-397.

Shaw, K. L., and S. P. Mullen. 2014. Speciation continuum. Journal of Heredity 105:741-742.

Shuker, D. M., T. M. King, J. L. Bella, and R. K. Butlin. 2005. The genetic basis of speciation in a grasshopper hybrid zone. Pages 423-450 in M. D. E. Fellowes, G. J. Holloway, and J. Rolff, eds. Insect evolutionary ecology. The Royal Entomological Society Symposium 22. CABI, Wallingford, UK.

Slatkin, M. 1975. Gene flow and selection in a two-locus system. Genetics 81:787-802.

Smadja, C. M., and R. K. Butlin. 2011. A framework for comparing processes of speciation in the presence of gene flow. Molecular Ecology 20:5123-5140.

Smadja, C. M., B. Canback, R. Vitalis, M. Gautier, J. Ferrari, J. J. Zhou, and R. K. Butlin. 2012. Large-scale candidate gene scan reveals the role of chemoreceptor genes in host plant specialization in the pea aphid. Evolution 66:2723-2738.

Smadja, C. M., E. Loire, P. Caminade, M. Thoma, Y. Latour, C. Roux, M. Thoss, D. J. Penn, G. Ganem, and P. Boursot. 2015. Seeking signatures of reinforcement at the genetic level: a hitchhiking mapping and can- 
didate gene approach in the house mouse. Molecular Ecology 24: 4222-4237.

Sobel, J. M., G. F. Chen, L. R. Watt, and D. W. Schemske. 2009. The biology of speciation. Evolution 64:295-315.

Soltis, D. E., R. J. A. Buggs, J. J. Doyle, and P. S. Soltis. 2010. What we still don't know about polyploidy. Taxon 59:1387-1403.

Soudi, S., K. Reinhold, and L. Engqvist. 2016. Ecologically dependent and intrinsic genetic signatures of postzygotic isolation between sympatric host races of the leaf beetle Lochmaea capreae. Evolution 70:471-479.

Szymura, J. M., and N. H. Barton. 1986. Genetic analysis of a hybrid zone between the fire-bellied toads, Bombina bombina and Bombina variegata, near Cracow in Southern Poland. Evolution 40:11411159.

- 1991. The genetic structure of the hybrid zone between the fire-bellied toads Bombina bombina and B. variegata: comparisons between transects and between loci. Evolution 45:237-261.

Tilley, S. G., P. A. Verrell, and S. J. Arnold. 1990. Correspondence between sexual isolation and allozyme differentiation - a test in the salamander Desmognathus ochrophaeus. Proceedings of the National Academy of Sciences of the USA 87:2715-2719.

Tregenza, T., V. L. Pritchard, and R. K. Butlin. 2000. The origins of premating reproductive isolation: testing hypotheses in the grasshopper Chorthippus parallelus. Evolution 54:1687-1698.

Turner, E., D. Jacobson, and J. W. Taylor. 2010. Biogeography of postmating reproductive isolation barriers is consistent with reinforcement in Neurospora, a model microbial eukaryote. Journal of Evolutionary Biology 23:1642-1656.

- 2011. Genetic architecture of a reinforced, postmating, reproductive isolation barrier between Neurospora species indicates evolution via natural selection. PLoS Genetics 7:e1002204.

Udovic, D. 1980. Frequency-dependent selection, disruptive selection, and the evolution of reproductive isolation. American Naturalist 116:621-641.

van Doorn, G. S., P. Edelaar, and F. J. Weissing. 2009. On the origin of species by natural and sexual selection. Science 326:1704-1707.
Vijay, N., M. Weissensteiner, R. Burri, T. Kawakami, H. Ellegren, and J. B. W. Wolf. 2017. Genomewide patterns of variation in genetic diversity are shared among populations, species and higherorder taxa. Molecular Ecology 26:4284-4295.

Vines, T. H., A. Dalziel, A. Albert, T. Veen, P. Schulte, and D. Schluter. 2016. Cline coupling and uncoupling in a stickleback hybrid zone. Evolution 70:1023-1038.

Wallace, A. R. 1889. Darwinism: an exposition of the theory of natural selection with some of its applications. Macmillan, London.

Wallace, B. 1988. Selection for the inviability of sterile hybrids. Journal of Heredity 79:204-210.

Wiens, J. J. 2004. Speciation and ecology revisited: phylogenetic niche conservatism and the origin of species. Evolution 58:193-197.

Wilson, D. S., and M. Turelli. 1986. Stable underdominance and the evolutionary invasion of empty niches. American Naturalist 127:835850.

Wright, K. M., D. Lloyd, D. B. Lowry, M. R. Macnair, and J. H. Willis. 2013. Indirect evolution of hybrid lethality due to linkage with selected locus in Mimulus guttatus. PLoS Biology 11:e1001497.

Yeaman, S. 2013. Genomic rearrangements and the evolution of clusters of locally adaptive loci. Proceedings of the National Academy of Sciences of the USA 110:E1743-E1751.

Yeaman, S., S. Aeschbacher, and R. Bürger. 2016. The evolution of genomic islands by increased establishment probability of linked alleles. Molecular Ecology 25:2542-2558.

Yeaman, S., and M. C. Whitlock. 2011. The genetic architecture of adaptation under migration-selection balance. Evolution 65:18971911.

Yukilevich, R. 2012. Asymmetrical patterns of speciation uniquely support reinforcement in Drosophila. Evolution 66:1430-1446.

Yukilevich, R., and J. R. True. 2006. Divergent outcomes of reinforcement speciation: the relative importance of assortative mating and migration modification. American Naturalist 167:638-654.

Associate Editor: Rebecca J. Safran Editor: Judith L. Bronstein

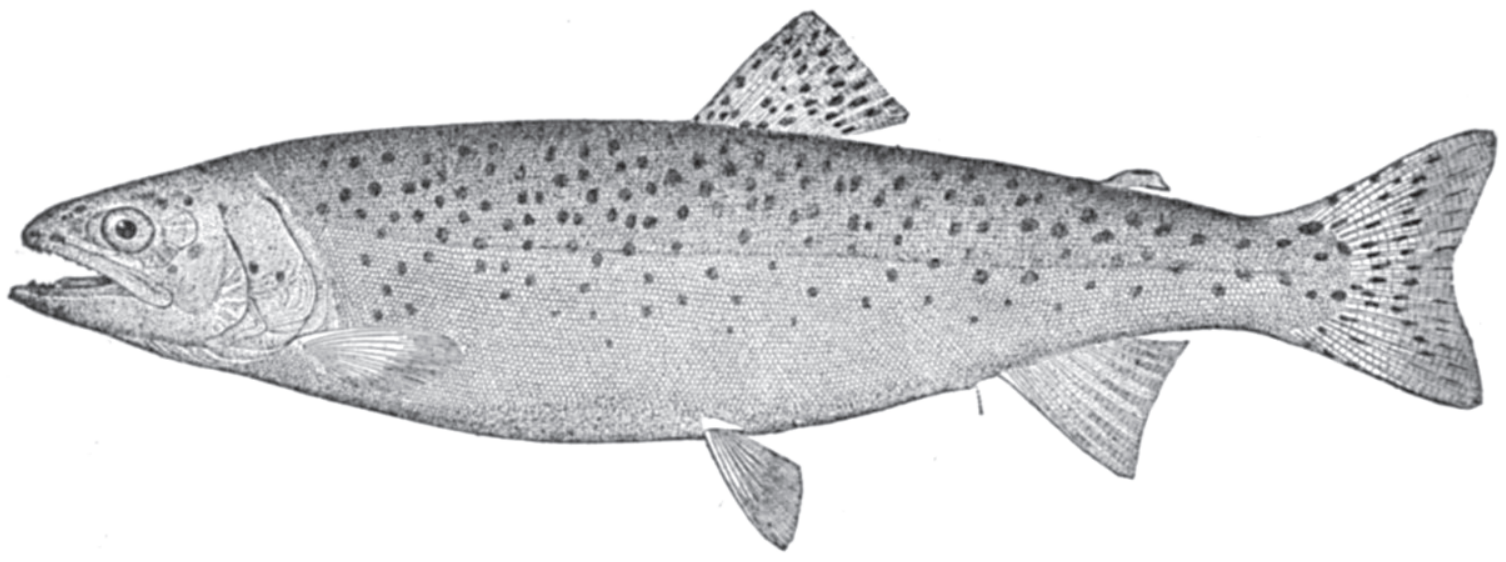

\footnotetext{
"This is the most widely-distributed and the most variable of our species. Northward, we have no certain knowledge of it beyond Unalaska; southward, it ranges to Mount Shasta, in California." Figured: "Clark’s Trout (Salmo purpuratus). Sitka, Alaska." From "Distribution and Some Characters of the Salmonidæ" by Tarleton H. Bean (The American Naturalist, 1888, 22:306-314).
} 